\title{
Additive effect of butorphanol in supraclavicular brachial plexus block
}

\author{
Sharan $\mathbf{R}^{1}$, Singh $\mathbf{M}^{2}$, Attri J.P $\mathbf{P}^{3}$, Singh $\mathbf{D}^{4}$ \\ ${ }^{1}$ Dr Radhe Sharan, Associate Professor, ${ }^{2}$ Dr Manjit Singh, Assistant Professor, ${ }^{3}$ Dr Joginder Pal Attri, Associate \\ Professor, ${ }^{4}$ Dr Davinder Singh, Junior Resident, All are affiliated with Department of Anaesthesia, Government Medical \\ College, Amritsar (Punjab), India.
}

Address for Correspondence: Dr Joginder Pal Attri, Associate Professor, Department of Anaesthesia, Government Medical College, Amritsar (Punjab), India. E-mail - jpattri12@yahoo.co.in

\begin{abstract}
Introduction: Increasing the quality of regional anaesthesia has always been an area of interest for anaesthesiologist. Butorphanol is a synthetic opioid analgesic having partial agonist at $\mu \&$ agonistic activity at kappa opioid receptor. It use has been done as a single drug as well as in combination with a local anaesthetic for axillary brachial plexus blockade. Material and Methods: 60 Patients were allocated randomly into one of the two groups of 30 patients each to receive supraclavicular brachial plexus block. In Group B, $30 \mathrm{ml}$ of $0.5 \%$ bupivacaine hydrochloride plus $1 \mathrm{ml}$ normal saline and in Group BB, $30 \mathrm{ml}$ of $0.5 \%$ Bupivacaine hydrochloride plus $1 \mathrm{ml}$ butorphanol $(2 \mathrm{mg})$. Onset time of sensory \& motor block, duration of motor block \& post operative analgesia was observed. Results: The mean duration of sensory block was $4.27 \pm 0.51 \mathrm{hrs}$ in group B and $9.10 \pm 0.71 \mathrm{hrs}$ in group BB and mean duration of motor block was $3.57 \pm 0.56 \mathrm{hrs}$ in group $\mathrm{B}$ and $5.13 \pm 0.51$ hours in group $\mathrm{BB}$. The difference in the two groups was found to be statistically highly significant $(<0.001)$. The duration of post operative analgesia was $5.27 \pm 0.77$ in group B and $11.37 \pm 0.85$ in group BB ( $\mathrm{p}<0.001$ ). Conclusion: Addition of butorphanol $2 \mathrm{mg}$ with bupivacaine prolongs the duration of blockade and postoperative analgesia in supraclavicular brachial plexus blockade without compromising the haemodynamic parameters or producing any significant adverse drug reactions.
\end{abstract}

Keywords: Butorphanol, Bupivacaine, Postoperative analgesia, Supraclavicular brachial plexus block

\section{Introduction}

Pain is one of the most unpleasant feelings encountered by a patient undergoing surgical procedure. As a poet had once said, "For all the happiness mankind can gain; is not in pleasure but in rest from pain". One of the greatest services a doctor does to his patient is to acquire skill in alleviation of pain. With passage of time newer drugs and techniques became available to the anaesthesiologists for relief of surgical pain but along with it came the realization of the various complications and inherent risks in anaesthetising a patient. Thus a need was felt for technique where an isolated part of body could be anaesthetised without affecting the whole body. When the mechanism of conduction of impulse through the nerves and its implications became known along with the discovery of local anaesthetic agents the various techniques of regional anaesthesia started to

Manuscript received $26^{\text {th }}$ April 2016

Reviewed: $14^{\text {th }}$ May 2016

Author Corrected: $24^{\text {th }}$ May 2016

Accepted for Publication $12^{\text {th }}$ June 2016 develop in earnest [1]. This is especially important in chronically ill patients or in those with serious systemic diseases such as diabetes, hypertension, cardiovascular, respiratory or renal diseases [2]. It is the anaesthesia of choice for emergency operations where the patient comes with full stomach and is at risk of aspiration. It has also been found to be relatively economical as compared to general anaesthesia [3]. Brachial Plexus Block in particular has more to offer in orthopaedic surgery than in any other surgical specialty, either alone or as a part of an anaesthetic sequence as it provides complete relaxation of muscles of upper extremities, sympathetic block of blood vessels which lessens postoperative vasospasm, pain and oedema and most importantly it helps patients to enjoy post-operative period free from nausea, vomiting and immediate postoperative pain. In 1884, Halstead first operated a patient under Brachial plexus block and like any other procedure it had its tide and ebb. Different techniques 
of brachial plexus block were described each having its own advantages and disadvantages. The different approaches are axillary approach [4], Supraclavicular approach, interscelene approach [5] and infraclavicular approach [6]. The advantages of the use of brachial plexus anaesthesia over general anaesthesia are apparent but it was still less used by anaesthesiologists due to few disadvantages like high failure rate, pleural injury causing pneumothorax and proximity to major vessels [7]. However, various newer techniques of depositing the drug perineurally and after identifying the nerves with nerve locator or with ultrasound have reduced these disadvantages to the minimum. [8,9].

Various investigators practiced supraclavicular approach and used a variety of local anaesthetic agents to perform an ideal and complete block. Advances have been made to search the new and safe anaesthetic agent to be used for the block. Various agents used are Lignocaine [10], Mepivacaine, Bupivacaine and Ropivacaine $[11,12,13]$. The analgesia can further be enhanced and prolonged by the addition of various adjuncts to the local anaesthetic drug. Various adjuncts used are opioids, vasoconstrictors, neostigmine, alpha 2 agonists etc. These drugs also reduce the dose of the local anaesthetic besides enhancing efficacy and reducing the incidence of adverse reaction [14]. In 2001 Karakaya D et al conducted a study to evaluate the anaesthesia and analgesic effects of Bupivacaine $0.25 \%$ alone versus bupivacaine $0.25 \%$ with $2.5 \mathrm{microgram} / \mathrm{ml}$ fentanyl in axillary brachial plexus block and concluded that addition of fentanyl almost double the duration of analgesia [15]. A study concluded in 2008 by using either $40 \mathrm{ml}$ of $1 \%$ lidocaine with $1 \mathrm{ml}$ of isotonic saline or $40 \mathrm{ml}$ of lidocaine with $2 \mathrm{mg}$ of butorphanol. It was concluded that addition of butorphanol $2 \mathrm{mg}$ to lidocaine $1 \%$ prolongs the duration of axillary brachial plexus blockade. Furthermore butorphanol can be used as an alternate to clonidine, tramadol, or dexamethasone to increase the duration of such blockade [16]

A study conducted Acharaya $\mathrm{R}$ et al in 2014 between $0.5 \%$ bupivacaine alone and bupivacaine and butorphanol $2 \mathrm{mg}$ in supraclavicular brachial plexus block taking 30 patients in each group had concluded that addition of butorphanol significantly prolong the duration of sensory as well motor block [17].

In present study, thus an attempt was made to undertake a comparative study of using bupivacaine-butorphanol combination in brachial plexus block for duration of analgesia as well as the onset and its side effects.
The supraclavicular technique was thus chosen for this study and has been carried out by injecting bupivacaine and bupivacaine-butorphanol combination through 22 gauge needle in a single shot application into the brachial plexus.

\section{Material and Methods}

The study protocol was a prospective, randomised, double blind, single-centre, in which 60 patients of American Society of Anaesthesiologists (ASA) grade I and II of age group 18 - 65 years of either sex, admitted in the orthopaedic department of Guru Nanak Dev Hospital, Amritsar and scheduled to undergo surgery of the upper limb or hand under supraclavicular brachial plexus block with bupivacaine alone and with combination of bupivacaine and butorphanol. A written informed consent was taken from all participants. The study was undertaken after the approval of institutions ethical and scientific committee. Patients were divided into two groups of 30 each and groups were allocated randomly using sealed envelopes. A sealed envelope was randomly selected and opened by an assistant, with instruction to draw the relevant drug. The syringe was labelled with the patient's name and was given to the investigator to perform the block. An independent observer then observed the onset of sensory and motor blockade and analgesia at 24 hours after blockade. Groups were named as Group B and Group BB.

- In Group B - $30 \mathrm{ml}$ of $0.5 \%$ bupivacaine hydrochloride plus $1 \mathrm{ml}$ normal saline

- In Group BB - $30 \mathrm{ml}$ of $0.5 \%$ Bupivacaine hydrochloride plus $1 \mathrm{ml}$ butorphanol ( $2 \mathrm{mg}$ ).

Patients allergic to study medications, with hhistory of significant neurological, psychiatric, neuromuscular, cardiovascular, pulmonary, renal or hepatic disease, with hhistory of alcohol or drug abuse, pregnant or lactating women, patients receiving chronic analgesic therapy, with morbid obesity i.e. BMI of $>35 \mathrm{~kg} / \mathrm{m}^{2}$, patients with coagulation disorders and patients on anticoagulation therapy and refusal by patient to enlist in study were excluded. A detailed pre-anaesthetic check-up of the patient selected for study was carried out a day before surgery and was recorded as per the Performa and all relevant and needed investigations were performed. The interpretation of the Visual Linear Analogue Scale was explained one day prior to the surgery to the selected patients taken for the study to determine the analgesia in the post-operative period. This was carried out with a $10 \mathrm{~cm}$ line. 


\section{Vas Score}

\begin{tabular}{|c|c|c|c|c|c|c|c|c|c|c|}
\hline 0 & 1 & 2 & 3 & 4 & 5 & 6 & 7 & 8 & 9 & 10 \\
\hline $\begin{array}{c}\text { No } \\
\text { Pain }\end{array}$ & \multicolumn{3}{|c|}{ Mild Pain } & \multicolumn{3}{c|}{ Moderate Pain } & \multicolumn{4}{c|}{ Severe pain } \\
\hline
\end{tabular}

All patients received Tab. Alprazolam $0.25 \mathrm{mg}$ orally one night prior to surgery. On the day of surgery, Inj. Glycopyrrolate $0.2 \mathrm{mg}$ and Inj. midazolam $0.04 \mathrm{mg} / \mathrm{kg}$ was given I/V as sedation before performing the block.

\section{Method}

Intravenous line was secured with 18G Angiocath and the patients were preloaded with $10 \mathrm{ml} / \mathrm{kg}$ body weight of Ringer Lactate solution over 15- 20 minutes. Multipara monitors were applied to record base line respiratory rate, pulse rate, non-invasive blood pressure, $\mathrm{SpO}_{2}$ and ECG. Oxygen was routinely administered via oxygen mask@6L/min. Premedication was given $\mathrm{I} / \mathrm{V}$ as described above.

Positioning of patient: Patients were in supine position with head facing away from the side to be blocked. The arm was in neutral position along the body or with the upper arm along the side, but with elbow flexed and the hand resting on the lower chest or abdomen.

Technique: In order to have complete cooperation of the patients, the procedure was explained to the patient before giving this block.

1. Position of the patient: The patient is placed in a supine position with the head turned away from the side to be blocked. The arm of the anesthetized should be adducted, and the hand should be extended along the side towards the ipsilateral knee as far as possible.

2. In the classic technique, the midpoint of the clavicle should be identified and worked.

3. The posterior border of the sternocleidomastoid can be easily palpated when the patient raises the head slightly. The palpating fingers can then rollover the belly of the anterior scalene muscle into the interscalene groove, where a mark should be made approximately 1.5 to $2.0 \mathrm{~cm}$ position to the midpoint of the clavicle. Palpation of subclavian artery at the site confirms the landmark.

4. After appropriate skin preparation, local anaesthetic was infiltrated at the needle insertion site. A $22 \mathrm{G} 100 \mathrm{~mm}$ insulated short bevelled needle was used. The needle was introduced at the specific land mark and a nerve stimulator was set at a current of $2 \mathrm{~mA}$ and a frequency of $2 \mathrm{~Hz}$. As the nerve was approached, movement of the wrist or fingers elicited and the current was gradually reduced to $0.4 \mathrm{~mA}$. The end point was taken when hand twitches could be elicited at a current of $0.4 \mathrm{~mA}$. On achieving this, the local anaesthetic was given in $5 \mathrm{ml}$ increments, aspiration before each bolus to avoid intravascular injection. Patients were monitored closely after completing the local anaesthetic injection.

Monitoring included respiratory rate, pulse rate, non-invasive blood pressure, ECG and oxygen saturation by pulse oximetry. After taking a pre-operative baseline value, patients were monitored at every 5 minutes interval till 30 minutes of local anaesthetic injection and then every 10 minutes till 1hour and then every 15 minutes till the end of surgery. During the whole operative procedure, the analgesia was closely observed. A constant watch was kept for observed development of any complications. Patients were assessed for loss of sensation to pin prick over the C5 - T1 dermatomes using a three point's scale every 2 minutes for the first 20 minutes and every 5 minutes thereafter till 30 minutes. The onset of motor block was evaluated based on the modified Bromage Scale. Sedation score was evaluated using four point scale. Further surgeons satisfaction score intraoperatively and as well as patient satisfaction score postoperatively were noted. A score of 2 for Sensory and 3 for Motor blockade was taken as successful block. Time of onset of sensory and motor blockade was recorded. The operation will be started when full surgical anaesthesia has developed. In case, patient experiences mild pain ( VAS >3 ) intra operative supplementation will be given with Inj. Ketamine $0.5 \mathrm{mg} / \mathrm{kg}$. General anaesthesia will be given to the patient of failed block or VAS > 3 and the case will be excluded from the study. At the end of the surgery assessment of sensory and motor blockade will be done. 
Research Article

\begin{tabular}{|c|c|c|c|c|}
\hline $\begin{array}{c}\text { Three point } \\
\text { sensory scale }\end{array}$ & $\begin{array}{c}\text { Bromage motor } \\
\text { scale }\end{array}$ & Sedation score & $\begin{array}{c}\text { Surgeon } \\
\text { satisfaction score }\end{array}$ & $\begin{array}{c}\text { Patient satisfaction } \\
\text { score }\end{array}$ \\
\hline 0- Sharp pain & 0- No paralysis & 1-awake; & 3- Excellent & 5- Excellent \\
\hline 1- Dull pain & 1- wrist flexion & $\begin{array}{c}\text { 2-drowsy but } \\
\text { responsive to } \\
\text { command; }\end{array}$ & 2- Satisfactory & 4- Very good \\
\hline 2- No pain & 2- elbow flexion & $\begin{array}{c}\text { 3- very drowsy but } \\
\text { responsive to pain; }\end{array}$ & 1-Unsatisfactory & $\begin{array}{l}\text { 3- Good } \\
\text { 2- Fair }\end{array}$ \\
\hline & 3- complete block & 4- unresponsive & & 1- Poor \\
\hline
\end{tabular}

Patients were monitored for 24 hours in the post-operative period for - Total duration of sensory blockade, total duration of motor blockade and total duration of post-operative analgesia.

No supplemental analgesic was given till the patient complained of pain, that is VAS score > 3 in the post-operative period. Rescue analgesia was given in the form of NSAIDS ( Inj. Diclofenac sodium ) or Opioids ( Inj. Tramadol ). The patients were monitored for side effects and complications of technique and drugs throughout intraoperative and postoperative period. Side effects and complications like accidental intravascular injection, pneumothorax, phrenic nerve block, neuropathy and horner's syndrome were recorded.

Analysis of data: Duration of analgesia was taken as the outcome measure of interest for the purpose of sample size calculation. It was estimated that 28 subjects would be required per group in order to detect a difference of 1 hour in this parameter between the two groups, $90 \%$ power and 5\% probability of Type 1 error. The data from the present study was systematically collected, compiled and statistically analysed after the completion of the study. Data are summarized as mean \pm standard deviation or as percentages. Numerical variables were normally distributed and were compared using Chi Square test for non-parametric data and Student's' test for parametric data using SSPS software 17 . P value of less than 0.05 was considered significant and less than 0.001 as highly significant. The results were analysed and compared to previous studies to draw relevant conclusions. The blinding was opened at the end of the study.

\section{Results}

The two groups taken were comparable with respect to age, sex, weight and ASA grade. Hemodynamic parameters recorded in both the groups was also statistically non- significant and no major change was seen with comparison to baseline value.

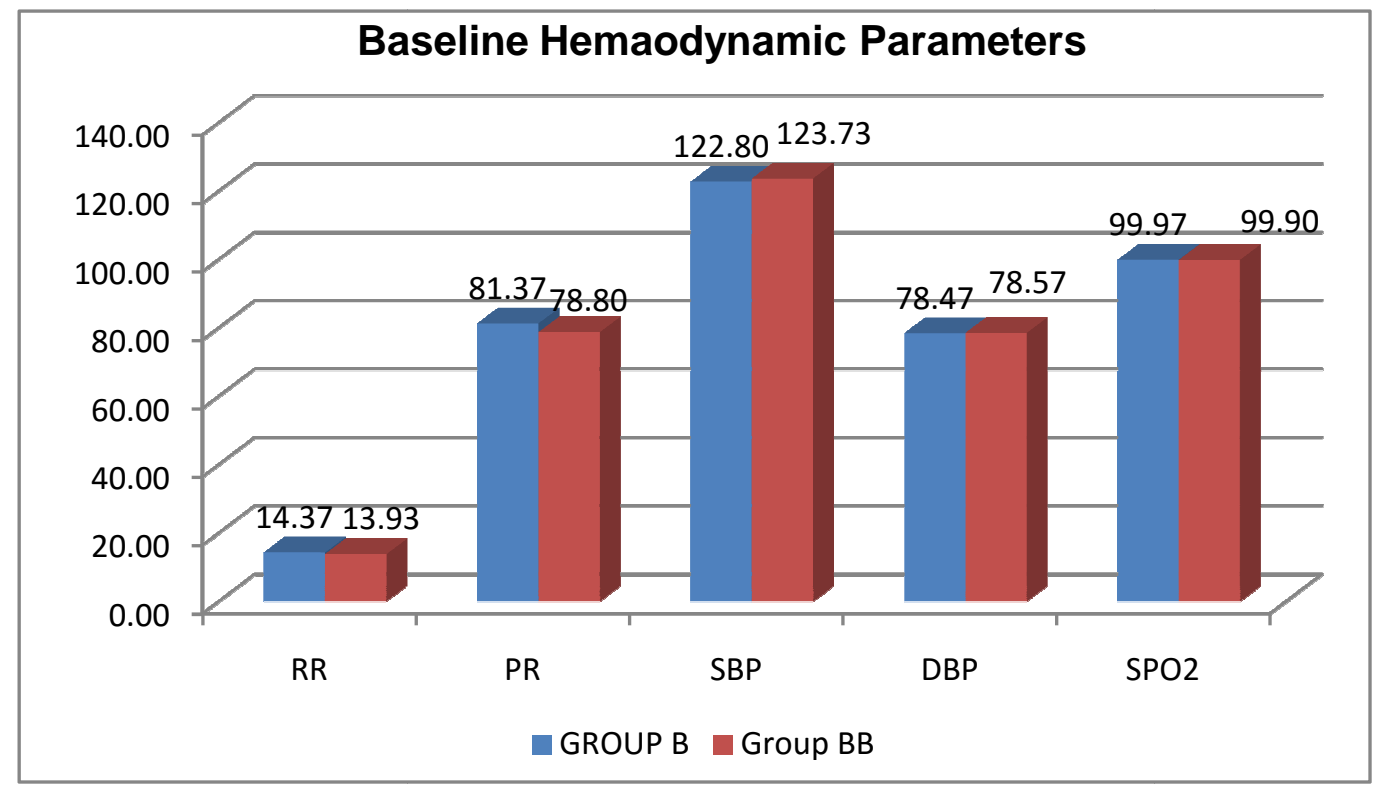


The mean onset of sensory block was $6.23 \pm 0.94$ minutes in group B and $6.00 \pm 0.95$ minutes in group BB. The difference is statistically Non significant $(p \geq 0.05)$ between the two groups. The mean time for onset of motor block was $7.80 \pm 1.06$ minutes in group B and $7.40 \pm 1.07$ minutes in group BB and the difference in the two was found to be statistically insignificant. ( $\mathrm{p} \geq 0.05$ ). During Surgery if the patient experienced mild pain (VAS score $>3$ ) then Inj ketamine supplementation $(0.5 \mathrm{mg} / \mathrm{kg})$ was given. Two patients $(6.7 \%)$ in group B and two patients $(6.7 \%)$ in group BB were given supplementary analgesia. The two groups were found to be comparable with respect to ketamine supplementation. The difference in the two was found to be statistically insignificant $(\mathrm{p}>0.05)$. The mean duration of surgery in group B was $71.33 \pm 20.88$ minutes and in group BB was $75.00 \pm 25.51$ minutes. The difference in the two groups was found to be statistically insignificant ( $p>0.05$ ). The mean duration of sensory block was $4.27 \pm 0.51 \mathrm{hrs}$ in group B and $9.10 \pm 0.71 \mathrm{hrs}$ in group BB. The difference in the two groups was found to be statistically highly significant $(\mathrm{p}<0.001)$ with group BB having longer duration.

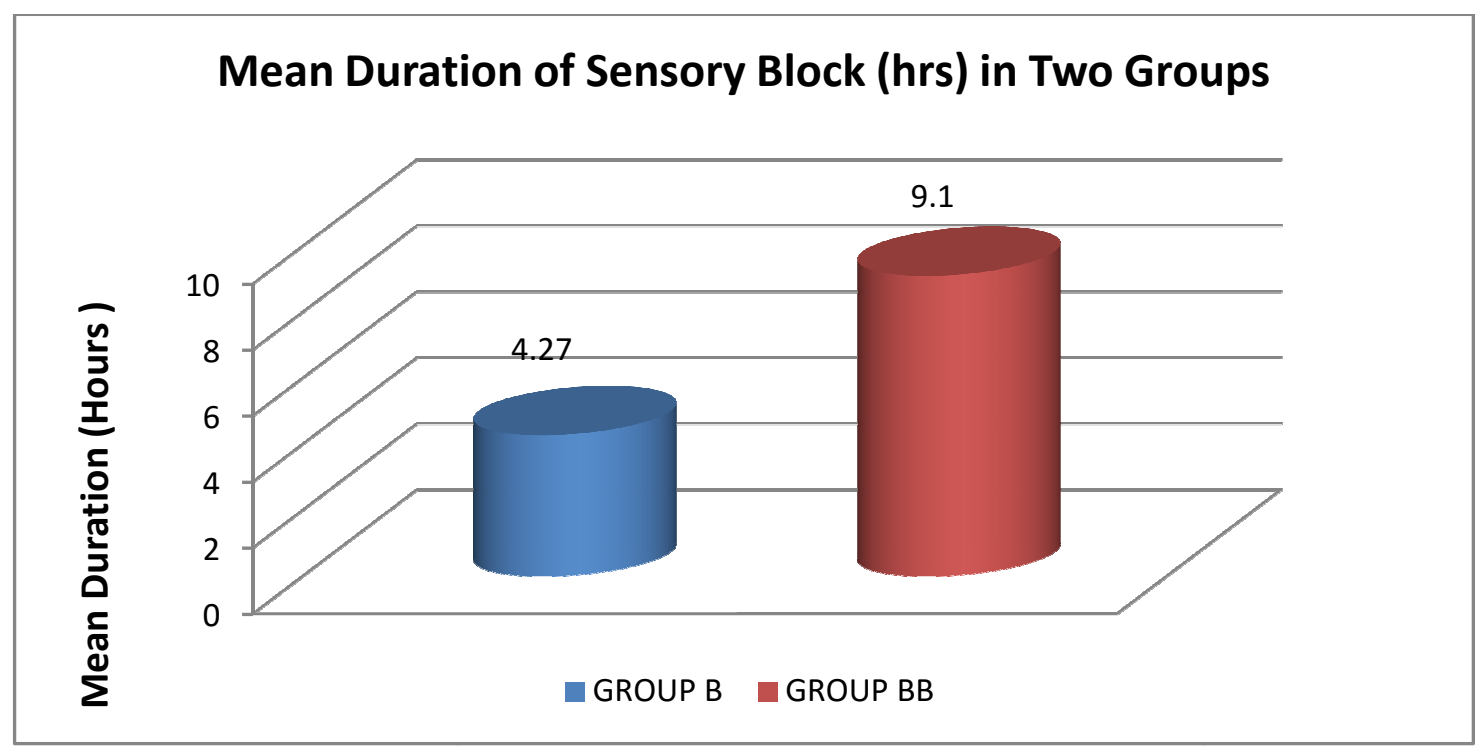

The mean duration of motor block was $3.57 \pm 0.56 \mathrm{hrs}$ in group B and $5.13 \pm 0.51$ hours in group BB. The difference in the two groups was found to be statistically highly significant $(<0.001)$ with having a longer duration of motor block in group BB.

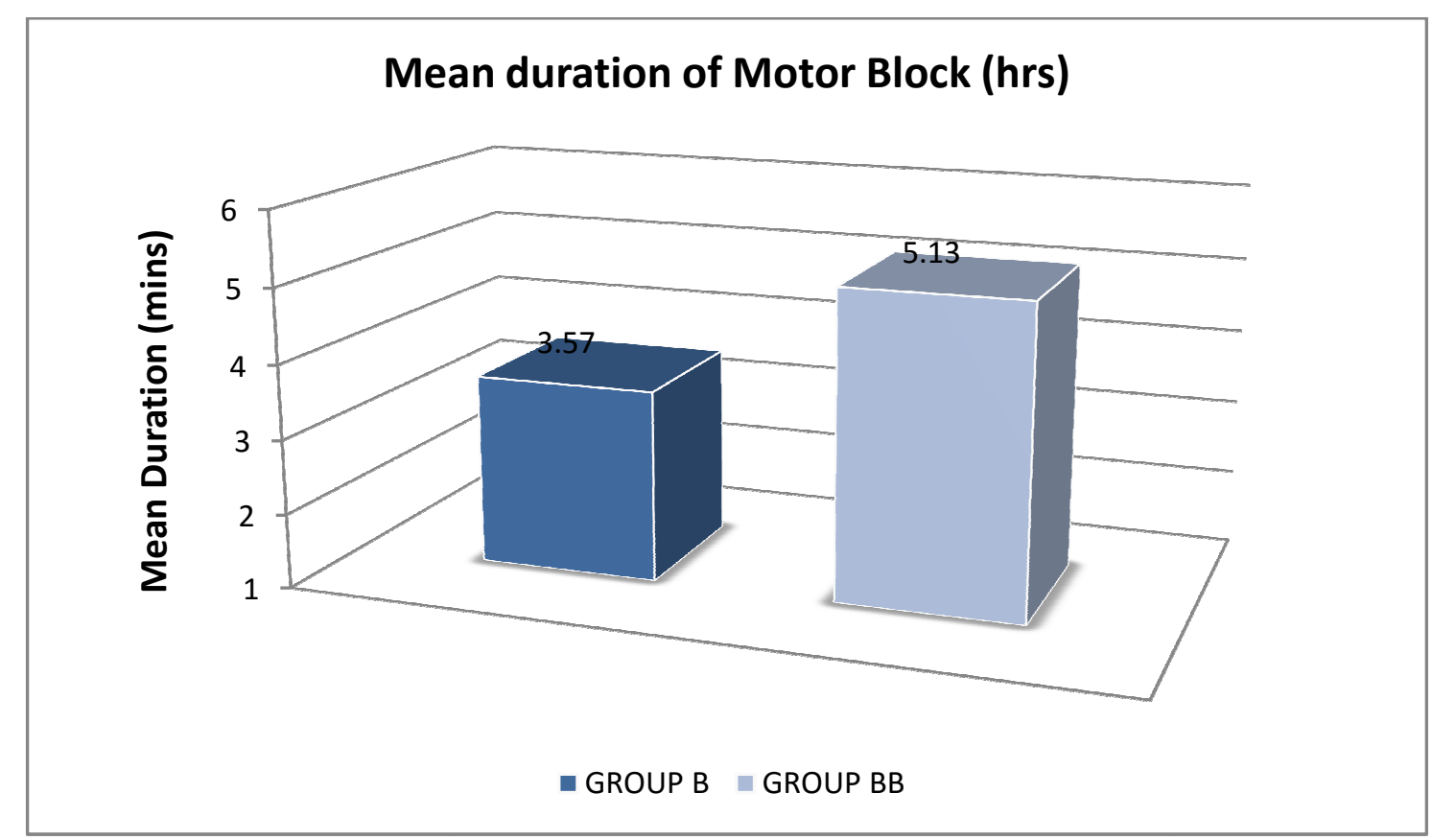


The duration of post operative analgesia was $5.27 \pm 0.77$ in group B and $11.37 \pm 0.85$ in group BB. The difference in the duration of analgesia in two groups was found to be statistically highly significant $(\mathrm{p}<0.001)$ with group B having a longer duration of post operative analgesia.

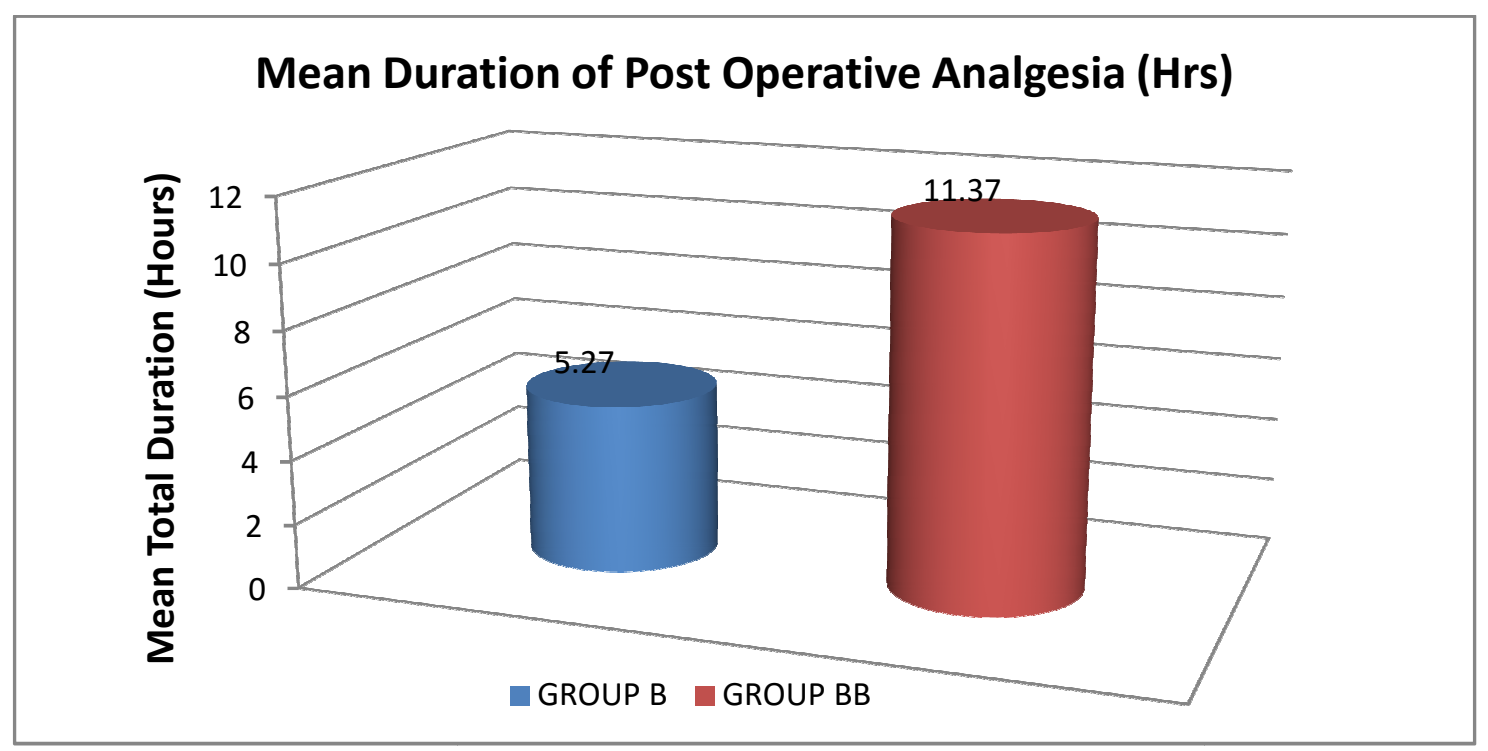

The mean number of analgesic doses in 24 hours in group B was $1.70 \pm 0.46$ while in group BB was $1.0 \pm 0.00$. The rescue analgesic used being injection diclofenac sodium. The difference in the two groups was found to be statistically highly significant $(\mathrm{p}>0.05)$.

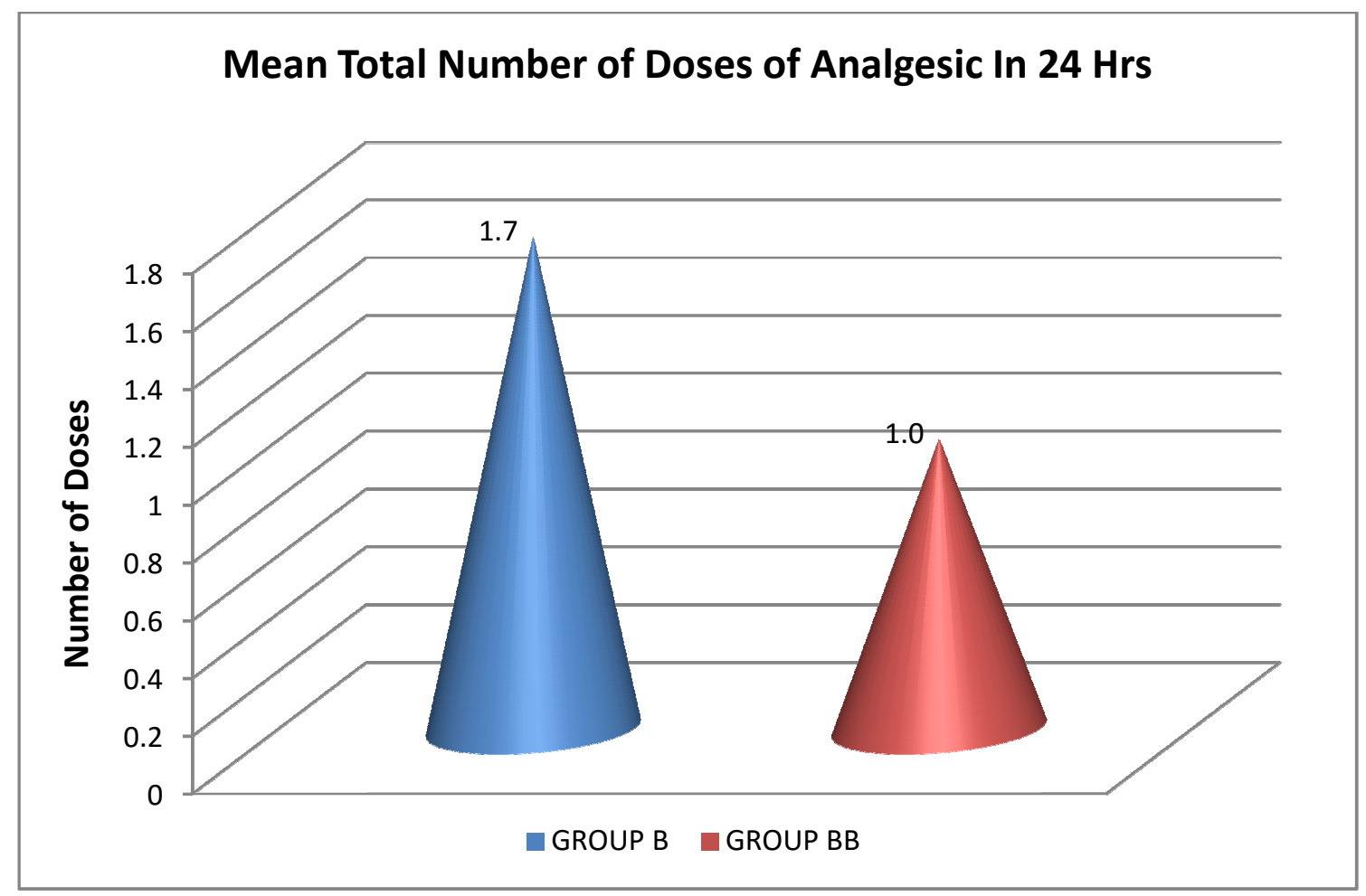

The complications in form of vascular puncture were noted in two patients in group B (6.67\%) and one patient in group in BB (3.33\%). Side effect in the form of bradycardia was noted in one patient in group B (3.33\%) and two (6.67\%) patients in group BB pruritus was noted in one patient in BB group. Otherwise, patients remained haemodynamically stable in both the groups. 


\section{Discussion}

In an effort to improve analgesia and facilitate mobilization, regional anaesthesia in the form of brachial plexus block in general and supraclavicular approach to brachial plexus in particular is often used either as an adjunct to general anaesthesia or as the primary anaesthetic in orthopaedic upper limb surgeries. Offering pain free period to the patient during postoperative time is essential on humanitarian grounds. It not only eliminates the stress response to surgery but also helps in smoother transition of the patient from surgery to the routine preoperative state. Laiden et al [18] showed that proteins undergo bidirectional axonal transport and speculated that these receptors circulate endorphins, their endogenous legends, in addition to exogenous opioids which proves that opioids act directly on peripheral nervous system.

The dose of Bupivacaine used in our study is $30 \mathrm{ml}$ of $0.5 \%$ thus being equal to $150 \mathrm{mg}$ of bupivacaine which is well within the maximum recommended dose of bupivacaine. Our dose of butorphanol that is $2 \mathrm{mg}$ is also in accordance with the dose of butorphanol recommended as adjuvant for brachial plexus block. The two groups taken were comparable with respect to age, sex, weight and ASA grade. Hemodynamic parameters recorded in both the groups were also statistically non- significant. The mean onset of sensory block was $6.23 \pm 0.94$ minutes in group $\mathrm{B}$ and $6.00 \pm$ 0.95 minutes in group BB which was in comparison to a study conducted by Acharya $\mathrm{R}$ et al [17], where sensory onset time in each nerve distribution with $30 \mathrm{ml}$ $(0.5 \%)$ bupivacaine was $6.1 \pm 1.02$ and when combined with butorphanol $2 \mathrm{mg}$ in supraclavicular brachial plexus block it was $5.8 \pm 0.62$. The mean onset of motor block was $7.8 \pm 1.064$ minutes in group $\mathrm{B}$ and $7.4 \pm$ 1.07 minutes in group BB. It is in accordance with the studies conducted by Acharya R et al [17] who reported to have mean onset of motor block at $7.4 \pm 1.05$ and $6.92 \pm 0.82$ minutes in group having Butorphanol. The mean duration of motor block was $3.57 \pm 0.56$ hours for group B and $5.13 \pm 0.51$ for group BB. The difference in the two groups was found to be statistically highly significant $(\mathrm{p}<0.001)$.

Our results for group B are in accordance with the duration of motor block reported by I.H.Mir et al [16] and Acharya R et al. [17] The mean duration of postoperative analgesia was $5.27 \pm 0.77$ hours in group $\mathrm{B}$ and $11.37 \pm 0.85$ in group BB. Thus, the difference in the two was found to be statistically highly significant ( $p<0.01)$, similar results were shown by Acharya R et al [17] that bupivacaine alone provide $312 \pm 0.44$ of duration of post-operative analgesia and bupivacaine with $2 \mathrm{mg}$ of butorphanol showed $663 \pm 0.51 \mathrm{mins}$. The VAS score remained zero at 240 minutes (4 hours) with Bupivacaine alone group and in bupivacaine plus butorphanol group it remained zero till 9 hours (540 minutes); which is in accordance with the study done by Acharya R et al [17].

The total number of doses in 24 hours was noted. The mean number of doses in 24 hours in Group B were 1.7 \pm 0.31 and in group BB $1.0 \pm 0.00$. The difference in the two groups was statistically significant $(\mathrm{p}<0.005)$. The complication that we encountered in our study was of vascular puncture that occurred in two $(6.67 \%)$ patients in Group B and one $(3.33 \%)$ patient in group BB with an overall percentage of $5 \%$ in our study. This is in accordance with the incidence of vascular puncture (017\%) reported by Macfarlane and Anderson [19].

There was no significant difference between the surgeon satisfaction score as well as Patient satisfaction score $(\mathrm{p}>0.05)$ in the two groups. Long-lasting postoperative analgesia may be regarded as beneficial outcome because it implies prolonged pain free recovery. Prolonged motor block, however, may not always be warranted, as ambulation may be delayed especially in patients undergoing surgery of a lower limb. Hence it was concluded that -

- Addition of Butorphanol to Bupivacaine prolongs both sensory and motor blockade duration as compared to Bupivacaine alone.

- No significant haemodynamic changes or any adverse effects are observed with the addition of Butorphanol with Bupivacaine.

Funding: Nil, Conflict of interest: None initiated. Permission from IRB: Yes

\section{References}

1. Papper EM, Brodie BB, Rovensteine EA. Postoperative Pain: Its use in the comparative evaluation of analgesics. Surgery 1952;32:107-9.

2. Chan VWS, Peng PWH, Kaszas Z, Middleton WJ, Muni R, Anastakis DG. A comparative study of general anesthesia, intravenous regional anesthesia and axillary 
block for outpatient hand surgery: clinical outcome and cost. Anaesth Analg 2001; 93: 1181-4.

3. Armstrong KP, Cherry RA. Brachial plexus anesthesia compared to general anesthesia when a block room is available. Can J Anaesth. 2004;51:41-4.

4. Hirschel G. Anaesthesia of Brachial Plexus for operations on upper extremity. Monchen Med Wochen Schr 1911;58:1555-6.

5. Winnie AP. Interscalene Brachial Plexus Block. Anaesthe Anal 1970;49:455 -66.

6. Raj PP, Montgomery SJ, Nettles D, Jenkins MT. Infraclavicular brachial plexus block - a new approach. Anesth Anal 1973;52:897-904.

7. Ward ME. The interscalene approach to brachial plexus. Anaesthesia 1974;29:147-57.

8. Eeckelaert JP, Filliers E, Alleman JJ, Hanegreefs G. Supraclacvicular brachial plexus block with the aid of nerve stimulator. Acta Anaesth Belgica 1984;35:5 - 17.

9. Karpal S, Krafft P, Eibenberger K, Fitzgerald R, Gosch M, Weinstabl C. Ultrasound guided supraclavicular approach for regional Anesthesia of brachial plexus. Anesth Analg 1994;78:507-13.

10. Palve $\mathrm{H}$, Kirvela $\mathrm{O}$, Olin $\mathrm{H}$. Maximum recommended dose of lignocaine are non toxic. $\mathrm{Br} \mathrm{J}$ Anaesth 1995;74:704-07.

11. Casati A, Vinciguerra F, Scarioni M, Cappelleri G, Aldegheri G, Manzoni $P$, et all. Lignocaine versus ropivacaine for continuous interscalene brachial plexus block after open shoulder surgery.Acta Anaesthesiology Scand 2003; 47:355-60.
12. Laura B. $0.75 \%$ and $0.5 \%$ ropivacaine for axillary brachial plexus block: A clinical comparison with $0.5 \%$ bupivacaine. Reg Anaesth pain Med 1999; 24: 514-18.

13. Thorton KL. Comparison of $0.2 \%$ ropivacaine and $0.25 \%$ bupivacaine for axillary brachial plexus block in paediatric hand surgery. Pediatric Anaesthesia 2003; 13: 409-12.

14. Khaled M. El-Radaideh, Yasser H. Al-Rashdan. The efficacy of Fentanyl as an adjunct to vertical Infraclavicular brachial plexus block performed with Lidocaine and Bupivacaine. J Med J 2008; 42:155-61.

15. Karakaya D, Buyukoz F, Baris S, Guldogus F, Tur A. Addition of fentanyl to bupivacaine prolongs anesthesia and analgesia in axillary brachial plexus block. Reg Anesth Pain Med 2001;26:434-8.

16. I. H. Mir, Hamid A. Addition of Butorphanol to lidocaine prolongs duration of the Axillary Brachial plexus Block. The Internet Journal of Anaesthesia 2007; 16:1.

17. Acharya R, Jena M, Mishra $S$ and Rath SK. Addition of butorphanol to Bupivacaine prolongs duration of supraclavicular brachial plexus block. International Journal of Applied Pharmaceutics 2014;6:8-10.

18. Laudren PM. Axonal transport of opiate receptors in capsaicin-sensitive neurons. BrainResearch 1984; 68: 413.

19. Young WS, Wamsley JK, Zabrin MA. Opioid receptors undergo axonal flow. Science1980;210:76-78.

\section{How to cite this article?}

Sharan R, Singh M, Attri J.P, Singh D. Additive effect of butorphanol in supraclavicular brachial plexus block. Int J Med Res Rev 2016;4(6):910-917doi: 10.17511/ijmrr.2016.i06.08. 